\title{
Being Interrupted: The Self and Schizophrenia
}

\author{
JOHN LYSAKER \\ University of Oregon
}

PAUL LYSAKER

Roudebush VA Medical Center, Indianapolis, IN; and

The Indiana University School of Medicine

A theory of the self seeks a comprehensive account of the elements whose interactions constitute a human being and the principles that govern those interactions. It must reckon with a vast array of phenomena, from perception and self-awareness to an infant's journey into adulthood; from language and labor to emotion, conscience, and mental illness. And it must do so in a way that recognizes that human beings are not simply instantiations of an eidos but unique, developing loci of life and activity. No two of us are alike. No one perceives, understands, or desires for another.

In this paper we want to explore what we regard as a fundamental facet of a human being: it engages in, even lives, as an ensemble of dialogues. Said otherwise, the locus of life and activity that we are is dialogical, and in the first place. We relate to others and ourselves, we plan, imagine, remember, and lust only on the basis of dialogical relations. Each of us is thus more than an atomistic entity. In elusive but crucial ways, our being is bound to and in some sense involves the presence of others, and our lives unfold as movements within ourselves and among others.

Even at the outset, it is crucial to note that our claim is not simply that selves employ narratives that synthesize their lives and that these narratives involve dialogues among various facets of a life. No doubt this happens, and we shall try to explain, at least in part, why and how. But our claim runs further than this. At base, that is, the very self whose life one might gather up and redirect through a narrative - that being is dialogical. To repeat, on our view, the self is dialogical in the first place, and thus a multiple phenomenon in and of itself, not simply in its self-representations.

Now, this is not to say that what follows provides a comprehensive account of the self. We have little to say about perception, memory, neurophysiol-

Journal of Speculative Philosophy, Vol. 19, No. 1, 2005.

Copyright (c) 2005 The Pennsylvania State University, University Park, PA. 
ogy, self-conscious and prereflective awareness of bodily states, and so forth. Nor are we claiming that one might develop a comprehensive account using only the elements that we employ, nor even that these elements are irreducible to other phenomena. Falliblists through and through, we have little interest in dictating what any account simply must say at the end of inquiry.

In order to demonstrate the power of a dialogical theory of the self, we will use it to interpret the phenomenon of schizophrenia, and in a way that preserves the participants' perspective, addressing what it is like to suffer from schizophrenia and what it means when persons with schizophrenia tell us that their sense of self has been fundamentally damaged or disrupted. More specifically, we will interpret the disruptions in sense of self that characterize schizophrenia as well as the persistence of various symptoms associated with schizophrenia, particularly: (a) hallucinations (or having sensory perceptions that others do not share); (b) delusions (or having beliefs that others deem idiosyncratic and grossly implausible); and finally (c) the diminishment of will and desire. This will show, we think, that a dialogical approach to philosophical anthropology, clinical and experimental psychological research, and psychotherapy promises to pay rich dividends.

Let's begin with something of an intellectual history of dialogical theory. The outlines of a dialogical conception of the self can be found in diverse places. Among a distinguished group, we find Bakhtin's reading of Dostoyevsky, Nietzsche's reflections on subjectivity, and Dewey's and Mead's social psychology particularly helpful. Interpreting the poetics of Dostoyevsky, Bakhtin (1985) asserts that humans are best described as polyphonic beings, products of an ongoing series of dialogues among distinct voices. Rather than revolving around singular, conclusive perspectives, Bakhtin holds that our sense of self emerges through conversations among functionally independent elements within persons. As an illustration, consider Dostoyevsky's description of Roskolnikov in Crime and Punishment: "sullen, gloomy, arrogant, proud ... insecure ...magnanimous and kind ... cold and callous ... always in a hurry, always too busy and yet he lies there doing nothing" (Dostoyevsky 1993, 215). The point is not that these are contradictory modes of a singular character, but that Roskolnikov's character is an evolving movement among complementary, contrary, and even contradictory facets.

An admirer of Dostoyevsky's psychological insights, Nietzsche also describes the self as a "subjective multiplicity." He argues that the self is best described as a "common wealth" or "a social structure composed of many souls" $(1966,26)$, offering the analogy that one person no more contains a singular self than Great Britain is a singular person. While the self and Britain may define themselves by certain events (e.g., a job or colonial holdings), both are composed of disparate elements that cannot be synthesized without remainder. At base, the claim is phenomenological. When observing one's feelings, thoughts, 
and behavior, one does not find a singular entity, but an ensemble of dispositions (self-as-assertive, self-as-shy) and roles (self-as-executive, self-as-guncollector) that often seem disconnected from or even at odds with one another.

In its origins, then, dialogical theory offers a self that is a complex ensemble of interanimating parts whose interactions are not driven by an overarching ego. Recently, Nietzsche's and Bakhtin's view has been taken up and subjected to more systematic inquiry, and their notion of a multiplicity of souls has been cast in terms of multiple self-positions, e.g., self-as-brother or self-as-anxious. Hermans alone (1996a; 1996b) and with colleagues (Hermans, Rijks, and Kempen 1993) has studied internal dialogue as manifest in structured interviews and concluded that self-coherence is maintained through interactions between self-positions or voices that are not centrally integrated. Analyzing individual patterns of verbalized self-presentation, Hermans suggests that dialogue is made possible by a temporary hierarchical arrangement of self-positions that periodically and spontaneously realigns itself with dominant self-positions retreating into the background and previously nondominant self-positions coming to the forefront. For example, suppose one is teaching a night class in a continuing education program, and one's therapist enrolls. In the classroom, self-asteacher will have to come to the fore whereas self-as-client will have to recede, and vice versa during sessions. Or, in order not to be a pedantic nuisance, a professor will need to move from self-as-educator to self-as-neighbor in order to establish friendships on her or his block. According to Hermans and his coauthors, it is precisely movement among and between disparate positions that integrates our sense of self.

Using semi-structured interviews Gregg (1995) also observes that an experience of self-coherence results from regular shifts within self-awareness. His focus, however, concerns the "places" that might allow such shifts to occur, labeling them "multistable or structurally ambiguous" symbols (617). For example, a self-position like "diamond in the rough" could be a multistable symbol that allows one to move among differing self-descriptions such as "crude," "dirty," "precious," and "refined." The point is not that "diamond in the rough" absorbs these self-descriptions. Rather, like Bakhtin, Gregg holds that the self is a matter of movement and negotiation among characteristics. He thus regards these multistable symbols as narratival elements that enable and sustain movement and negotiation.

Although our terminology differs from Gregg's, we read these multistable symbols as self-positions in their own right. Our reasoning begins with a phenomenological reconstruction. Across one's life, various self-positions interact with one another, thus creating opportunities for generalizations about one's life with regard to those positions. (As we will see later, life histories and their generalizations are generated from their own self-positions and are thus dialogical as well.) If, for example, one performs well in a variety of social roles (say 
student, athlete, and piano player), one may come to regard oneself as a "success." Life histories gather around many such symbols, however. Thus one simultaneously may regard oneself as a success, as lonely, as a coward, etc., and these symbols can no doubt come into contact and conflict with one another. For example, one's sense of self-as-success, when confronted with self-as-lonely, may shrink in scope, leaving one as self-as-success with regard to solo activities but self-as-failure with regard to social ones. Second, as time passes, multistable symbols will have to engage emergent self-positions, e.g., self-as-parent. Given this possibility of dialogue among multistable symbols, and dialogue between existent multistable symbols and emergent self-positions, we think it reasonable also to regard these integrating symbols as self-positions, as aspects of the self that belong to and participate in (rather than reign over) an ensemble of positions among which one continually moves.

While the multistable symbols Gregg locates may be regarded as selfpositions, they are self-positions of a special sort: they directly refer to other self-positions. Unlike self-positions such as self-as-brother or self-as-student, self-as-success arises through an explicit synthesis of other self-positions. True, self-as-brother implicates other positions, e.g., self-as-son, but playing that role does not require one explicitly to take up being a son. Self-as-success, however, is explicitly concerned with those positions wherein one has met with success.

Given the presence of multistable symbols that nevertheless can function as self-positions in their own right, it seems justifiable to distinguish two kinds of self-position: "first-order-positions" and "metapositions." We speak of positions like self-as-author as "first-order" because they operate within our lives in nonreflexive manners. Other positions, such as self-as-failure, are in part tied to reflexive acts, however, and thus we term them "metapositions," albeit only in a grammatical sense. The point is not that metapositions reflect the insight or activity of a self that floats above the many self-positions whose negotiation we are. Rather, such self-positions are metapositions because they concern how one should regard other self-positions, much as metaphilosophy concerns how one should regard philosophy.

Our protestations to the contrary, one might still expect to find an integrating author at the core of dialogical activity, particularly with regard to metapositions. We see no reason to suppose this. As Hume argues, we have no knowledge of ourselves as having any "perfect identity and simplicity" (1888, 251). He continues: "I never catch myself at any time without a perception, and never can observe any thing but the perception.... I may venture to affirm of the rest of mankind, that they are nothing but a bundle or collection of perceptions, which succeed each other with an inconceivable rapidity, and are in a perpetual flux and movement" (252). True, acts like perception and desire are grammatically referred to subjects who perceive, desire, etc., but reflection suggests that such reference is specious with regard to any substantial entity. As Emerson writes in "The Oversoul," "Man is a stream whose source is hidden. Our being 
is descending into us from we know not whence" (Porte and Morris 2001, 163) . Once again, the claim is phenomenological, and in a manner freed from the kind of grammar-driven arguments that often lead one to grope about for a transcendental ego. Thoughts, feelings, and even the insights that form the basis of metapositions, as they are given or disclosed, come to us rather than respond to our summons, and without any attendant apparent author. As Emerson states in "The Method of Nature," " I conceive of man [sic] as always spoken to from behind and unable to turn his head and see the speaker" (87).

Now, in the context of an account of the self, one mustn't be misled by a prevailing obsession with the epistemic subject and regard self-positions primarily in terms of representations or even propositional attitudes, as if they were the fruits of a reflexive act of self-interpretation and best understood as judgments about the self. First, judgments about the self are parasitic upon firstorder self-positions, for those in part constitute the self being judged. One can see this in metapositions. One is a self-as-failure only in reference to first-order positions that one enacts poorly. One might say, twisting Hume a bit, that one never finds oneself without a self-position. Second, and this we will argue in more detail shortly, no self-position is disconnected from desire and activity. Self-positions are thus not merely a matter of how we perceive ourselves, but also of what and how we are.

In place of Hume's bundle of perceptions, then, we would rather speak of a bundle of habits, agreeing with Dewey that "All habits are demands for certain kinds of activity; and they constitute the self" $(1988,21)$. We are drawn to employing a language of habits for several reasons. First, the language of habit captures the prereflective nature of most human activity, from walking to shaking hands. Even movement among self-positions seems to occur without selfconscious choice. When walking down the street in a foreign city, for example, I inhabit the role of tourist, most likely behaving in ways that do not call attention to myself. If I suddenly and unexpectedly see a friend, however, I'll begin to wave and smile, and act as a "friend," and all without having "decided" to leave self-as-tourist behind in favor of self-as-friend. The point, then, is that for the most part, we live on autopilot. As Nietzsche writes, "For we could think, feel, will, and remember, and we could also 'act' in every sense of the word, and yet none of all this would have to 'enter our consciousness' (as one says metaphorically)" (1974, 297). Now, one may find Nietzsche's remark exaggerated. We, however, do not. Athletic and musical performances involve extremely complex behaviors. But as many have testified, the self-conscious election of movements or actions, even in virtuoso performance, is not only not required, but often a hindrance. It would appear, then, that inhabiting and moving among self-positions occurs prereflectively, and drives the self in a habitual manner.

The language of habits also merges self-positions with desire and activity, thus clarifying how self-positions function in human behavior. Consider, for example, the habit of gambling. Self-as-gambler marks a set of capacities (I 
know how to gamble), a set of desires (I seek the ends associated with gambling, even if not wholeheartedly), and an objective tendency to engage in those activities. Or, consider the self in an affective and metapositional manner. Selfas-angry marks a set of capacities (e.g., to yell, seek revenge, interfere, etc.), desires (e.g., to frighten, to harm, to undermine, to release steam), and an objective tendency to get angry. On our view, then, self-positions are bound to motivation and action, more a matter of the pragmatics of subjectivity than of their propositional content concerning oneself. And it is principally because self-positions are bound to what Dewey terms an "inherent tendency to action" that we regard them as habits.

It is perhaps worth stressing that not only first-order self-positions operate habitually. Metapositions are habitual as well. While the position of self-assuccess may emerge in a reflective moment, it need not remain merely reflective. In the spirit of James's "The Will to Believe," and as much self-esteem research suggests, positive self-regard may lead one to try new and novel things, that is, it too is tied to a disposition to act in certain ways. For example, the metaposition self-as-success would involve a range of activities in which one has been and expects to be successful (e.g., playing the harmonica, learning languages, or more generally, just doing things), some desires (i.e., to continue to succeed in whatever one does), and a disposition to act in certain ways, e.g., to take risks (or one might come to fear failure and thus keep to those activities in which one has been successful).'

Our final reason for regarding self-positions as habits involves the way in which the concept "habit" draws self-positions outside a pure interiority. Bound to rhetoric of representation, self-interpretation, and even self-perception, selfpositions remain mere ideas we have about ourselves. Once self-positions are construed along the lines of habits, however, the capacities they involve are bound to the worldly scenarios that solicit and sustain them. The self-position self-as-gambler will not arise unless there are situations in which one can gamble. Likewise, the self-position self-as-melancholic will not arise unless loss, death, and the passage of time are in some sense there for one to dwell upon. We thus agree with Dewey that habits and thereby self-positions "may be profitably compared to physiological functions like breathing, digesting. The latter are, to be sure, involuntary, while habits are acquired. But ... habits are like functions ... in requiring the cooperation of organism and environment" (Dewey 1988, 15).

Now, one should not construe a habit's cooperation with its environment in epistemically secure terms, as if grounding in a habit ensured that self-positions were predicated on reliable, prereflective knowledge of the world. Such an inference would not only be wrong, it would miss the point and risk ensnaring us once again in an epistemic frame. Rather than championing a kind of animal faith at the root of self-positions, our point concerns the dependency of habits on worldly relations, one that renders them transactional, the feature of a being whose life is structurally bound to and reflects engagements with a surrounding 
world. Even delusional self-positions, e.g., self-as-alien, are tied to scenarios within which they are enacted, e.g., a distant planet, a space ship, persecution by the CIA, etc. Thus rather than securing the veracity of those beliefs concerning the world that are correlates of self-positions, thinking of self-positions in terms of habits performs a more general service. It brings them out into the world such that any given self-position is a function of and a contributing force to a thoroughly relational phenomenon, i.e., human being.

It is crucial to maintain a relational conception of the dialogical self because dialogue is not simply an internal event but an interpersonal one as well. Said otherwise, one's internal polyphony develops and moves in response to social demands. As Emerson writes, "What do we not owe to the call which society makes upon the slumbering abilities of each individual?" (Whicher 1964, 18). First, first-order self-positions are bound to social roles like student, sibling, or parking lot attendant? We speak of "social roles" here for several reasons. Individuals do not create these positions, but inherit them. Moreover, the community at large distinguishes them from other positions in ways that are normatively binding in a loose sense (e.g., studying is normally not part of being a parking lot attendant and being related by blood is not required to be a fellow student). Positions like that of student are thus not only socially generated, but what is generated amounts to a cluster of practices, expected behaviors, and outcomes, the performance of which involves discernable social actions, e.g., enrolling in and possibly attending classes, satisfying requirements, and graduating. And as we have already intimated, multistable metapositions are implicitly and often explicitly tied to social roles. One is a diamond in the rough or a success with reference to things one could become or one already is, e.g., a good partner or a reliable colleague. Or, one is destructive in contexts that one destroys, e.g., romantic relationships and family gatherings, and in a particular role, e.g., as a lover or an in-law. Second, metapositions are often generated from the standpoint of particular social roles. The self-position diamond-in-therough might arise for a self-in-therapy, or a larger, more complex life history involving several metapositions might be told from the standpoint of self-asautobiographer.

While constitutive of the self, social roles are nevertheless personal, or better still, personalized. If only for survival's sake, social roles must be individuated by those who play them. I may be a carnivore but learn to avoid certain meats that upset my stomach. Also, through interaction with other self-positions, social roles cannot help but be personalized, e.g., an orphan with siblings is adopted into a family without children that later becomes wealthy. These changing circumstances will individuate the manner in which she is a "daughter." She begins as daughter/sibling-as-orphan, then daughter/sibling-as-orphan/adoptedonly-child, then daughter/sibling-as-orphan/adopted-only-child/heir-to-a-fortune. Thus, while self-positions are bound to social roles, their relation is a true relation and not a unidirectional process of construction. 
At this point, a certain degree of readerly exasperation may be mounting: "You invoke notions like life histories, and still you deny the presence of an authorial ego amid manifold self-positions. Where's the sense in that?" In order to clarify our resistance to the expectation that informs this kind of frustration, let us return to an earlier point. Following Hume and Nietzsche, we see nothing beyond a grammar-led prejudice at the core of an insistence on the need for a transcendent ego reigning over self-positions.' Still, it is reasonable to ask how we account for the emergence of life histories that contribute to and thicken whatever coherence one has in one's sense of self. In addressing this question, you will see that our allegiance to Nietzsche in this context is not limited to his negative insight. We also adhere to his claim that "consciousness has developed only under the pressure of the need for communication" $(1974,298)$.

In order to develop Nietzsche's insight, we will make use of Habermas's reading of Mead (Habermas 1987; 1992).' Let's return to the personalization of social roles. Operative in communicative action (i.e., action oriented toward mutual understanding) is another pressure individuating social roles. Individuals perform speech acts like expressions, questions, and promises. I cannot promise for you, you cannot accept an apology for me, and neither of us can express the other's intentions.' Communicative competence requires, therefore, that we present ourselves to others as individuals, both as speakers and as addressees. But let's explore the matter further.

A source of social integration, communication enables us to coordinate actions. If it is to do so, one needs to know what another is going to do, and as an individual, not as a generic brother, professor, or customer. Learning to communicate involves, therefore, learning to meet an expectation performatively intrinsic to communication, to speak for oneself as a singular being. One finds a similar expectation in the related practice of communicating needs. The expression of needs requires speech acts in the first person. If I am to receive what I want or you are to provide me with what I need, I must make my needs plain to you. These, no doubt, will be bound to social roles, that is, my needs will arise vis-a-vis various roles that I play, e.g., teacher or friend, but unless I can express myself in the first person, they will only be ineffectively met.

Not only expressive speech acts require the first person, however. All speech acts do. Even when one refers to impersonal events, such as how many miles lie between Eugene, Oregon and Ghent, Belgium, one is still expected to provide reasons for one's beliefs should others find them puzzling, and the same holds for conduct. In communicative action, we are expected to answer for what we say, do, and believe, and strictly speaking, others cannot answer for us. Should one attempt to answer for us, we will still be asked, "Is that what you meant?"

We have dipped into Habermas's theory of communicative action because it shows how, in acquiring communicative competencies, we acquire not only linguistic capacities but modes of self and other relation that encourage and even require us to adopt a first person perspective. Integrating his view with 
ours, the claim is that the "I" of first person speech becomes a structural element in all self-positions, one dialogically tethered to actual and possible interlocutors and grounded in the habits required for communicative competence. In other words, the "I" of first-person speech is also a transactional, dialogical phenomenon. It is a source neither of agency nor of spontaneous judgment-those are tied to the habits that collect around and constitute other self-positions. Instead, it is an acquired capacity for self-regard that amounts to an internalized sense of another's regard for one, a regard that less interjects into one a content-rich identity than expects one to answer for what one says and does.'

On Habermas's view, and here we follow him, our communicative capacity for self-regard lies at the root of life histories. Moreover, and here we are extending his work into current discussions of the dialogical self, we contend that it is the communicative capacity for self-regard that enables the emergence of metapositions and the sense of self that they facilitate. The claim is that communicative competence makes self-knowledge possible, the kind that later forms the basis of life histories. Communicative competence entails learning how to answer for one's beliefs and actions. It thus demands a self-interrogation whose fruits can be shared with and scrutinized by others, i.e., expressed linguistically. Nietzsche succinctly summarizes the point: "The human being inventing signs is at the same time the human being who becomes ever more keenly conscious of himself. It was only as a social animal that man [sic] acquired self-consciousness-which he is still in the process of doing, more and more" (Nietzsche 1974, 299). Note that Nietzsche's point is not that self-representations construct the self through a quasi-transcendental constitution, but that under the pressure to communicate, human beings have come to performatively orient themselves toward themselves such that self-exploration and linguistic self-presentation have become possible.

By integrating Habermas's theory of communicative action with a dialogical theory of the self, we are able to see how life histories are thoroughly dialogical and not the product of a central, authorial ego. First, their subject matter concerns the various self-positions and metapositions within which our life unfolds, e.g., child, student, mechanic, etc. As a narrative, a life history thus involves a dialogue among these positions. Second, life histories are not generated by some amorphous "I." Rather, and this repeats an earlier point, to say "I" in the context of a life history is simply to take responsibility for previous and prospective actions and beliefs. Habermas writes: "Standing within an intersubjectively shared lifeworld horizon, the individual projects himself as someone who vouches for the more or less clearly established continuity of a more or less self-consciously appropriated life history" (Habermas 1992, 168). As far as the actual telling is concerned, one will have to look again at determinate self-positions and the social locations they involve. For example, one might gather the events of one's life in therapy, or while applying for a job, or as one ages and faces a crisis of meaning. Finally, the positions from which life histo- 
ries are gathered can themselves enter into dialogue with other self-positions. Thus self-as-memoirist may come into contact with self-as-truthful, or self-intherapy may come into contact with self-as-self-sufficient. Or a life history may produce its own metapositions, e.g., self-as-victim that comes to function proactively alongside other self-positions. Life histories and the coherence they bring about are thus dialogical at the level of their formal preconditions and at the level of content. Not only do they involve a synthesis of positions, but one pursues them from dialogically situated positions as well and on the basis of a dialogically generated capacity.

You have before you, then, a sketch of what is involved in regarding the self as a dialogical phenomenon. As a complex entity, a "multiplicity of souls," to use Nietzsche's language, the self is composed of at least two kinds of selfpositions: first-order self-positions often involving social roles, e.g., self-as-author; and metapositions that refer to and comment upon first-order self-positions, e.g., self-as-diamond-in-the-rough. Though categorically distinct, first-order positions can come to function in metapositional ways, e.g., self-as-criminal; and metapositions can function as first-order positions when they come to operate prereflectively in our worldly engagements.

Within a self, self-positions are interanimating, to use Bakhtin's term, meaning the life of a self is a life of movement and interaction among selfpositions. One kind of movement occurs in life histories where relations between first-order positions are examined and synthesized, often through the generation of multistable metapositions like self-as-success. Such histories are thoroughly dialogical as well, in terms of the capacities that enable them-arising, as they do, out of our acquisition of communicative competence-the subject matter that concerns them, and the self-positions from which they are generated.

Following Dewey, we regard the life and movement of self-positions in general as a matter of habit. We thus do not regard them as principally representational phenomena. Instead, they are intertwined and partly constitute the existential praxis that forms the bases of our being-in-the-world. Moreover, we do not find at the source of their movements-which includes the human actions they inform-any authorial subject, either in the form of a perpetually spectating ego or a spontaneous source of agency.

With this conception of the self as an ongoing event of dialogical exchanges and syntheses in mind, let us turn now to interpreting a variety of phenomena characteristic of schizophrenia. Since it was first proposed as a distinct type of "psychiatric disorder," discussion regarding schizophrenia has expanded. Symptoms have included odd sensory experiences and beliefs, sometimes called positive symptoms (Schneider 1959), radically diminished desire, sometimes called negative symptoms (Carpenter et al. 1988; Kraeplin 1974), tenuous connections between thoughts (Bleuler 1950; Spitzer 1997), discreet deficits in memory and attention (Green 1996; McGhie and Chapman 1961), autism (Bovet 
and Parnas 1991), unmodulated anger (Freeman 1969), and social deviance (Szasz 1970). Causal explanations of these symptoms have appealed to factors such as selective abnormalities in neurodevelopment (Andreasen et al. 1998), neurological degeneration (Fucetola et al. 2000), obstetric complications (Kendell et al. 2000), communication deviance (Wahlberg et al. 2002), social stigma (Markowitz 1998; Wright et al. 2000), and oppressive power relations (Rudge and Morse 2001).

Unlike the debate concerning manifest or objective features, inquiry into the subjective experience of schizophrenia has found a more uniform phenomenon. The impact of schizophrenia has been likened to scenes of destruction and devastation. Images like the collapse of a home after the erosion of its foundation or an orchestra without a conductor have been employed (Minkowski 1987). Indeed, persons with the illness often describe themselves as having been inextricably damaged. For example, as a young man with schizophrenia explained, "I used to be extroverted, outgoing, and happy," but now he could not bear to talk to others and had hopelessly "lost the person who I used to be." It was not that he was a different person. Instead he had become empty, his life since the "illness" spent lying in bed, hallucinating, and awaiting the discovery of the "right medicine." Even persons with schizophrenia who deny that anything is "wrong" often describe a world in which a personal cataclysm can be clearly inferred. For example, a middle-aged man, after reporting that he was not mentally ill, acknowledged that he was lost nonetheless. Part of his mind, he said, had been removed the night before by female spirits. Even within potentially empowering delusions, one often finds the same sense of loss. As another middleaged man described, "Just because I'm a god doesn't mean I'm not a nothing. 7

Considered as a whole, the disruption in sense of self that accompanies schizophrenia has been characterized in terms of enduring agony (Searles 1965; Robbins 1993), or a sense of isolation and rejection (Bassman 2000; Lysaker and Bell 1995) that is qualitatively distinct from existential uncertainties about fate or role (Lysaker and Lysaker 2002; Sass 1992; Selzer and Schwartz 1994). Persons with schizophrenia may also experience a fragmentation of self where aspects of themselves no longer cohere or are not embedded in an intelligible history (Eigen 1986; Frosh 1983; Holma andAaltonen 1997; Laing 1978; Lysaker et al. 2002; Rosenfeld 1954). Moreover, these profound alterations in self-conception are entwined with altered experience of the world (Holma and Aaltonen 1995). Common activities such as grocery shopping can prove either so meaningful or meaningless that they are impossible to participate in (Bovet and Parnas 1993; Sass 1992). Similarly, personal agency may appear to exist wholly outside the self (Frith 1992; Jaynes 1976; Lysaker et al. forthcoming).

In the midst of multiple symptoms and clinical features, we thus almost always find here the felt experience of self-destruction. Now, if self-coherence arises in an interanimating dialogue among and between first order self-positions and metapositions, both within and outside of life histories, could a dis- 
ruption in the flow of dialogue compromise a person's sense of self? Could disruptions in internal conversation affect self-experience in a manner that parallels the reports and observations detailed above regarding schizophrenia? In a previous paper (Lysaker and Lysaker 2002) we have suggested as much.

First, dialogue could cease if self-positions of either sort were no longer ordered in a way that enabled one to respond adequately to experience. For example, positions such as self-as-brother, self-as-unlovable, self-as-in lovewith-Karen, and so forth, might serially emerge in a context where none are particularly called for; for example, while waiting to pay for groceries. In other words, if something happened so that individual voices were no longer ordered by a patterns of shifting dominance of self positions, the structure of dialogue could disintegrate, possibly making it appear that "the conductor," or source of agency, had disappeared. It could also seem that everything had fallen into the metaphorical equivalent of a heap of rubble. Multiple self-positions would remain but without organized interaction.

A second way in which internal dialogue could be disrupted involves an inverse process. Instead of disorganization, what if a few self-positions, or even a solitary position, gained dominance? If singular self-positions ordered all conversation within and without, the self would only circulate among a limited range of monologues. Then, what was formerly a rich array of self-positions would be tyrannically denied entry into the conversation. In this instance, sense of self would be sustained by a lone voice (e.g., "I am persecuted" or "I am allpowerful"), as opposed to the cacophony described above. The myopia of such a monologue would relentlessly tax any sense of self. In a monologue of persecution, for example, former friends would become foes, and any interaction that formerly evoked positive or loving traits would be annulled by the suspicion of ulterior motives. Likewise, previously entertaining events that supported aspects of self related to casual interests, such as going to a see a movie, would be transformed into waves of insidious assault. For persons in such a state, it is not difficult to see how, if they recalled their earlier life, they might conclude that parts of themselves had been lost or destroyed.

What, though, of the symptoms characteristic of schizophrenia? On our view, the disruptions in dialogical capacity that contribute to a collapse of self may fuel or be fueled by the major symptom clusters in schizophrenia. We are not claiming that dialogical impairment "causes" schizophrenia. We are suggesting, however, that positive and negative symptoms amplify and are amplified by difficulties in sustaining dialogue within the self and with others. In other words, dialogical disruptions are a pathway by which self-disturbances and symptoms influence one another.'

The first class of symptom possibly linked to dialogical disturbance involves positive symptoms, including delusions (unfounded and implausible beliefs) and hallucinations (sensory phenomena experienced as having a mind-independent existence that others deny). Examples of hallucinations in- 
dude hearing and seeing persons no one else does, while examples of delusions include convictions that one is the subject of a worldwide conspiracy, is dead, and/or has supernatural abilities (American Psychological Association 1994). Given our interest in dialogue we will focus upon two positive symptoms: a) complex verbal hallucinations or hearing "voices" that command or make complex utterances to or about the individual; and b) systematized delusions whose beliefs explain a wide range of phenomenon . $^{9}$

To date, systematic surveys suggest that complex hallucinations are common in acute (Benjamin 1989) and post-acute (Nayani and David 1996) phases of schizophrenia. Complex auditory hallucinations frequently express the intention to regulate the hearer's behavior and seem omnipotent (Birchwood et al. 2000; Chadwick and Birchwood 1994; Davies et al. 1999; Leudar and Thomas 2000). Beyond causing specific behaviors, hallucination, according to Gilbert et al. (2001), may trigger innate fight/flight defenses within the hearer. Of particular interest to us are two related points about content and the relationship of the person to the hallucination. First, complex hallucinations tend to communicate focused, singular messages. One might hear, for instance, that one is to die, that one should flee, or that one is God. Second, the hallucination does not invite the hearer into dialogue. As described by Bakhtin (1981), in a dialogical relationship, different voices "interanimate each other" or bring significance and complexity to one another through their interaction. In a hallucination, hearers may fear, loath, love, or hate the voice in question, and they may debate with themselves or others the meaning of the voice's message (e.g., Benjamin 1989; Davies et al. 1999; Leudar and Thomas 2000). They also may shout at or distract themselves from the voice, but the voice is generally not construed as something they can influence or can talk with.

Consider, for example, a man who explained he was no longer whole since portions of his brain had been stolen by female voices. He often heard the spirits talk about or to him and felt that they had done something to him. Yet they were fundamentally not a presence that could be touched or influenced by his words. They were omnipotent. It was meaningless for him to comment on their remarks, debate them, or give them an order. On the whole, then, hallucinations are experienced as a unidirectional source from which singular messages flow, urging a person to act and/or feel in a certain way.

Whether these voices have their root in abnormal spontaneous cortical activity in the centers that support language (David 1994) or any other source, we would suggest that their impact on the dialogical self is clear. Barraged by authoritative commands, internal conversation is imperiled. First, given constant interruptions, it suffers just as many find it hard to think and function in the presence of loud, banging noises. Second, just as one's deliberations appear futile in the face of an overwhelming authority, so one besieged by hallucinations wielding omnipotence would be silenced and absorbed into what he or she was commanded to do and be. Our suggestion, then, is that as hallucinatory 
voices gain strength, one's usual dialogical movements are interrupted and colonized by the monologue delivered by the hallucination. As the man who experienced female voices taking parts of his brain away explained, he said he was a computer, and the voices, the programmers. From the complementary perspective of his therapist, it seemed that the voices provided a monologue that was beyond question and that subsumed his identity. ${ }^{10}$

Turning to systematized delusions, we similarly suggest that they may compromise dialogical capacity. As noted, systematized delusions are stable ways of explaining and linking together a wide range of potentially unrelated events. Like complex verbal hallucinations, they incline a person to view the world in a singular manner and are not regarded as matters for dialogue or reflection. Instead, systematic delusions form an unassailable starting point around which one revolves, and not vice versa. Because of their impregnability, we suspect that systematized delusions strain one's ability to sustain diverse internal conversations and impel one toward a state in which the self-positions associated with the delusions are increasingly embraced at the expense of other self-positions or dialogue among positions. Consider, for example, a man who believed himself the subject of a global conspiracy. As he explained, the presence of his persecutors left him with only two emotions, "rage and panic," that overrode whatever self-position might emerge or be solicited in a social exchange. Consistent with this, conversations with him in psychotherapy were quite one-sided or monological. Whenever discussing personal matters he presented himself in terms of a self-as-angry/fearful that was a victim of omnipotent forces. Questions about his history or personal complexities were "totally irrelevant" in his eyes, as were questions about the history or complexities of the omnipotent. Interestingly, this man loved anthropology and could talk about it knowledgably and without idiosyncrasy as long as it did not involve him personally. Thus, when not considering himself, he seemed able to negotiate multiple self-positions (e.g., self-as-poetry-lover, self-as-interlocutor, etc.), but whenever a selfrelation was drawn out in conversation, this fluid movement among self-positions was swept up into a monological stream of persecution.

Thus far we have attempted to illustrate how the presence of verbal hallucinations and systematized delusions generally hinder the richness and diversity of internal dialogue. Before we turn to another symptom, we also wish to suggest that the relationship of positive symptoms to dialogue may be circular, developing momentum as distinct self-positions are absorbed. Just as positive symptoms imperil dialogue, disruptions in internal dialogue may heighten positive symptoms. Our hypothesis is that with fewer self-positions available the singular impelling voice of the hallucination or delusion may gain strength. Put another way, if one has few voices within oneself, it might prove increasingly difficult not to follow and be defined by one's symptoms. For example, with a loss of self-positions (e.g., student, son, friend), there would seem to be fewer and fewer resources from which to draw the strength to reject a delusion or hallucinated command. With fewer previous self-positions available it would 
seem necessarily more difficult to reject delusions or hallucinations by saying "That is not me," or "That is not the kind of person I am."

At the phenomenological level, then, we find two processes that could feed off of one another. Decrements in dialogical capacity and thereby in sense of self may heighten vulnerability to positive symptoms. Second, positive symptoms could infect self-positions and corrode the social relations each entails, turning teachers, parents, and lovers into one more persecuting force, leaving the self with only the voice of a victim. As a possible illustration of this we turn again to the man whose mind was being stolen by female voices. As psychotherapy progressed, he expressed more and more complex self-positions. He retained the voice of someone humiliated and injured but also allowed to surface, in a more reflective, nuanced manner, the voice of someone thirsting for revenge, who enjoyed antisocial practices, and was also deeply ashamed. To us this suggests that with greater dialogical capacity he could resist certain positive symptoms and with fewer positive symptoms his dialogical capacity could deepen.

While positive symptoms entail the presence of something unexpected, negative symptoms suggest the absence of something, such as emotion, social interest, or desire. (APA 1994). The prevailing view is that negative symptoms have unique etiological roots and are functionally independent of positive symptoms (Andreasen et al. 1990). For our purposes we wish to consider two specific negative symptoms: flat affect, or a lack of emotional expression; and disturbance of volition, the absence of any meaningful sense of direction in life. A person who might be described as having blunted affect would show a limited range of emotion, perhaps appearing wooden or lifeless in the midst of a celebration or time of sadness. In contrast to a depressed person who might silently be consumed by pain, someone with flat affect would feel emptiness. In parallel, someone experiencing a disturbance of volition would be unable to initiate goal-directed activity or make purposeful decisions about his life course. As one man explained, the source of his disability was not his positive symptoms. Instead, not having a direction in life was crippling him (Lysaker and Bell 1995).

As with positive symptoms, we suggest that these negative symptoms could disrupt internal dialogue and be affected by disruptions in dialogue. If one experiences a decrease in affect, might the strength of certain self-positions erode, disrupting the capacity to play various social roles? Recall the different facets of Crime and Punishment's main character: "sullen, gloomy, arrogant, proud ... insecure ...magnanimous and kind ... cold and callous ... always in a hurry, always too busy and lies there doing nothing." What if the affects that bound together the proud, insecure, callous, and gloomy self-positions were significantly weakened? Without enough animating affect, how could one be proud, insecure, or gloomy? Moreover, without affect, what would compel one to fulfill the expectations that help define social roles? Our suggestion is that bereft of affect, a self-position falls out of any hierarchy and virtually disappears from internal dialogue, just as one's self-position as political actor falls out of inter- 
nal dialogue if one is politically apathetic. This is not to say that there is a simplistic, linear relationship between affect and dialogue. But if dialogue is an interanimating process, without enough animating force of affect, it might largely halt.

Self-positions are not only animated by the presence of affect, however, but also by their participation in the larger narratives that give meaning to particular struggles and events. For example, being a student is animated in part by working toward a degree that will edify and improve employment opportunities. But what if the sense of life direction that binds together and solicits selfpositions integral to being a student fell to the way side (e.g., self-as-hard-working and self-as-communicative)? It strikes us that such a person would no longer experience themselves as a hard worker, for they would have nothing to work toward. Our second suggestion, then, is that bereft of orienting purposes, selfpositions lack animation and thus lie dormant.

As with positive symptoms, we also think that the interaction of negative symptoms of dialogical capacity is bidirectional or circular. If one is unable to draw together the various self-positions that are integral to being a student (e.g., classmate and hard worker) the project itself (e.g., contributing to group projects and tracking down sources) would prove disjointed and incoherent. Likewise, the desirability of the end, here graduating, would wane if the means were no longer available. Consider the hypothetical person who has lost the ability to sustain conversation internally. Our suggestion is that in the wake of a loss of dialogical capacity, the individual could be swept into a position where, to reduce confusion and a feeling of failure, dedication to various projects and feeling for particular opportunities and events would lessen, thus contributing to a cycle of decline.

Note that we are not claiming that with loss of affect or direction in life all inner conversation stops. Rather, our claim is that the self-positions that belong to life projects and about which one is enthused or anxious would remain mostly dormant, leaving one with basic self-positions, associated with meeting subsistence needs, whose emergence remains relatively isolated. Devoid of multiple and interacting self-positions, such a self would have little to talk about and little would unfold in the course of a life story. In such a state a person might turn the ownership of their self-conception over to others or limit that understanding to a superficial account or "press release," that is, one devoid of the comparisons and syntheses that evolve into metapositions and give us a sense of continuity over time. And with little sense of who one might be over time, devotion to complex, long-range projects would wane.

As an illustration, consider another man with schizophrenia who, when asked for his side of his life's story, found the question absurd. He thought it was "funny" that it was a "doctor" asking, because only a doctor could understand the contours of his life. When challenged, he could describe being angry with his wife for not letting him drive to the grocery store, but beyond that, elements of his dialogues were terse and unconnected, and did not extend into 
the future as elements of an unfolding, purposive story. It seems that his negative symptoms curtailed his dialogue, and as his dialogue dwindled so did his affect and direction in life.

At the outset of this article, we asked how we might understand the emergence and persistence of symptoms concurrent with the disruption of self-experience in schizophrenia. In a reply derived largely from a dialogical conception of the self, we have suggested that one's very sense of self and the many, diverse symptoms characteristic of schizophrenia are intimately related to compromises in how well one can sustain dialogues among diverse aspects of the self. We've argued in particular that a collapse in coherent dialogue could naturally lead to the illusion of self-destruction, and that such a collapse might exacerbate and be exacerbated by certain positive and negative symptoms. Thus symptoms and self-experience may be distinct in schizophrenia but also might mutually affect one another via the thread of dialogical disturbance. Symptoms may disrupt dialogue, which then disrupts self-experience; and/or a disruption in dialogue may both compromise sense of self and exacerbate symptoms, all leading to the many tragic trajectories well known to those who suffer from or treat persons with this illness.

More generally, our purpose has been to articulate further a dialogical theory of the self, and to show not only how it can inform a philosophical anthropology, but also how, by illuminating schizophrenia as a subjective phenomenon, it can also productively contribute to experimental and clinical psychological inquiry. No doubt, much more remains to be done if a dialogical conception of the self is to take its place among prevailing conceptions of the self, and to prove its mettle among the many approaches available to those who would work with and empower those who suffer from schizophrenia. We take the results shown here to offer some evidence for optimism.

\section{Notes}

1. It is important to note that we are not claiming that each action flows from a single selfposition and the habits associated with it. No doubt most action is the result of multiple selfpositions and metapositions. Thus, for example, self-as-courageous may combine with self-assuccess and produce a risk taker, whereas self-as-success combined with self-as-socially-insecure might produce a risk-aversive character.

2. How one comes to inhabit these roles is a complex subject for developmental psychology, and beyond the scope of this paper. No doubt many processes are operative, e.g., parental instruction, mimicry, play, internalization of expectations, etc.

3. Nietzsche repeats this charge throughout Beyond Good and Evil, e.g., in the preface and, in one way or another, across $\$ \$ 12-20$ of part 1 (Nietzsche 1966). One also finds the thought in the first essay of On the Genealogy of Morals, $\$ 13$. For an article comparing Nietzsche's critique to Hume's, see Davey 1987.

4. At this point, our concern is not whether or not Habermas has Mead right. Instead, we want to use Habermas's account-which arises out of a reading of Mead-because it enables us to understand the emergence of metapositions and life-histories within the context of a dialogical self.

5. One can interpret another's intentions or speak on his or her behalf, but these speech acts are distinct from expressing an intention. 
6. Now, we are not claiming that the acquisition of communicative competence is the source of either consciousness or self-consciousness. Rather, our claim is that the ability to say " $\mathrm{I}$ " profoundly influences the emergence and development of self-positions. As to where consciousness and self-consciousness come from, that is something we cannot address here. We will say, however, that the "I" of our speech-acts does not directly refer to consciousness and/or self-consciousness. Moreover, it would appear that one doesn't need either concept to explain our ability to say "I," or, to echo Nietzsche, our ability to make promises.

7. All quotations are taken from clinical sessions conducted by Paul Lysaker. In order to protect anonymity, names have been omitted and the details of the stories changed.

8. Concerning this relation between the symptoms of schizophrenia and the collapsing sense of self that characterizes the subjective experience of those who suffer from it, it seems too simple to suggest that one causes the other. Persons with a variety of other medical conditions including Alzheimer's disease, head injury, or stroke can experience any number of symptoms similar to those of schizophrenia without an analogous subjective perception of destruction. Similarly, a coherent sense of self can exist among persons without a medical condition who nevertheless hallucinate or embrace any number of unusual beliefs or convictions (Leudar and Thomas 2000). Conversely, a sense of personal destruction fails to account adequately for the cognitions and behaviors that make up the criteria for schizophrenia in diagnostic manuals. Many persons feel as if their lives are coming apart without undergoing hallucinations or bouts of paranoia. Reductive explanations thus fail in either direction.

9. In analyzing these phenomena, our concern is to understand their role in and impact upon self-experience. Our inquiry is thus not competing with those that explore the potential biological bases of positive symptoms (Andreasen et al. 1990; David 1994). Even if caused by physiological disturbances, positive symptoms, like any disturbance, would still impact one's sense of self.

10. It is worth noting that hallucinations (and delusions as well) might provide a self-position or two capable of providing some sense of self. For example, the man whose brain had been robbed by voices nevertheless heard repeatedly that he was "precious." Such positions would be limited, however, to the role and life granted them by the imperative delivering hallucinations, and thus would not spawn dialogical movement, but suspend it.

\section{Works Cited}

Amador, X. F., M. Flaum, N. Andreasen, D. H. Strauss, S. A. Yale, S. C. Clark, and J. M. Gorman. 1995. "Awareness of Illness in Schizophrenia and Mood Disorders." Archives of General Psychiatry 51: 826-36.

American Psychiatric Association. 1994. Diagnostic and Statistical Manual IV. Washington, DC: American Psychiatric Association.

Andreasen, N. C., M. Flaum, V. W. Swayze, G. Tyrrell, and S. Arndt. 1990. "Positive and Negative Symptoms in Schizophrenia: A Critical Reappraisal." Archives of General Psychiatry 47: 615-21.

Andreasen, N. C., S. Paradiso, and D. S. O'Leary. 1998. "Cognitive Dysmetrica As an Integrative Theory of Schizophrenia." Schizophrenia Bulletin 24: 203-18.

Bakhtin, M. 1981. The Dialogic Imagination. Trans. C Emerson. Austin: University of Texas Press. . 1985 [1929]. Problems of Dostoyevsky's Poetics. Trans. C. Emerson. Minneapolis: University of Minnesota Press.

Bassman, R. 2000. “Agent, not Objects: Our Fight To Be.” Journal of Clinical Psychology 56: 1395-411.

Bebout, R. R., and M. Haris. 1995. "Personal Myths about Work and Mental Illness.” Psychiatry 58: 401-4.

Benjamin, L. S. 1989. "Is Chronicity a Function of the Relationship Between the Person and the Auditory Hallucination?" Schizophrenia Bulletin 15.2: 291-310.

Bleuler, E. 1950 [1911]. Dementia Praecox or the Group of Schizophrenias. Trans. J. Zinkin. New York: International Universities Press. 
Birchwood, M., A. Meaden, P. Trower, P. Gilbert, and J. Plaistow. 2000. "The Power and Omnipotence of Voices: Subordination and Entrapment by Voices and Significant Others." Psychological Medicine 30: 337-34.

Borges, J. L. 1962. Labyrinths: Selected Stories and Other Writings. New York: New Directions Press.

Bovet, P., and J. Parnas. 1991. "Autism in Schizophrenia Revisited." Comprehensive Psychiatry 32: 7-21.

. 1993. "Schizophrenia Delusions: A Phenomenological Approach." Schizophrenia Bulletin 19: 579-97.

Calasso, R. 1994. The Marriage of Cadmus and Harmony. Trans. T. Parks. New York: Vintage International.

Carpenter, W. T., D. W. Heinrichs, and A. M. Wagman. 1988. "Deficit and Nondeficit Forms of Schizophrenia." American Journal of Psychiatry 145: 578-83.

Carroll, A., S. Fattah, Z. Clyde, I. Coffey, D. G. C. Owens, and E. C. Johnstone. 1999. "Correlates of Insight and Insight Change in Schizophrenia." Schizophrenia Research 35: 247-53.

Chadwick, P., and M. Birchwood. 1994. "The Omnipotence of Voices: A Cognitive Approach to Auditory Hallucinations." British Journal of Psychiatry 164: 190-201.

Davey, N. 1987. "Nietzsche and Hume on Self and Identity." Journal of the British Society of Phenomenology 18: 14-29.

David, A. S. 1994. "The Neuropsychological Origin of Auditory Hallucinations." In The Neuropsychiatry ofSchizophrenia, ed. A S. David and J. C. Cutting. Mahwah, NJ: Lawrence Erlbaum.

Davidson, L., and J. Strauss. 1992. "Sense of Self in Recovery from Mental Illness." British Journal ofMedical Psychology 65: 131-45.

Davies, P., P. Thomas, and I. Leudar. 1999. "Dialogical Engagement with Voices: A Single Case Study." British Journal of Medical Psychology 27: 179-87.

Dewey, John. 1988 [1922]. The Middle Works ofJohn Dewey. Vol. 14,Human Nature and Conduct. Carbondale: Southern Illinois University Press.

Dostoyevsky, Fyodor. 1993 [1866]. Crime and Punishment. New York: Alfred A. Knopf.

Duckworth, K., V. Nair, J. K. Patel, and S. Goldfinger. 1997. "Lost Time, Found Hope and Sorrow, the Search for Self, Connection and Purpose During Awakenings on the New Antipsychotics." Harvard Review ofPsychiatry 5: 227-33.

Eigen, M. 1986. The Psychotic Core. New York: Jason Aronson.

Frankel, B. 1993. "Groups for the Chronic Mental Patient and the Legacy of Failure." International Journal of Group Psychotherapy 43: 157-72.

Freeman, T. 1969. The Psychopathology ofthe Psychoses. New York: International Universities Press.

Frese, F. J. 1993. "Twelve Aspects of Coping for Persons with Schizophrenia." Innovations and Research 2: 39-46.

Frith, C. D. 1992. The Cognitive Neuropsychology ofSchizophrenia. Hove: Lawrence Erlbaum.

Frosh, J. 1983. The Psychotic Process. New York: International Universities Press.

Fucetola, R., et al. 2000. "Age and Neurologic Function in Schizophrenia: A Decline in Executive Abilities Beyond That Observed in Healthy Volunteers." Biological Psychiatry 48: 137-46.

Gilbert, P., M. Birchwood, J. Gilbert, P. Trower, J. Hay, B. Murray, A. Meaden, K. Olsen, and J. N. V. Miles. 2001. "An Exploration of Evolved Mental Mechanisms for Dominant and Subordinate Behavior in Relation to Auditory Hallucinations in Schizophrenia and Critical Thoughts in Depression." British Journal ofMedical Psychology 31: 1117-27.

Green, M. F. 1996. "What Are the Functional Consequences of Neurocognitive Deficits in Schizophrenia?" American Journal of Psychiatry 1533: 321-30.

Gregg, G. S.1995. "Multiple Identities and the Integration of Personality." Journal ofPersonality 63: 617-41.

Habermas, Jiirgen. 1987 [1981]. Theory ofCommunicative Action. Vol. 2. Boston: Beacon Press. . 1992 [1988]. Postmetaphysical Thinking. Cambridge, MA: MIT University Press. 
Harding, C. M., J. Zubin, and J. Strauss. 1992. "Chronicity in Schizophrenia." British Journal of Psychiatry 161 (supp. 18): 27-37.

Hermans, H. J. M. 1996a. "Opposites in a Dialogical Self: Constructs as Characters." Journal of Constructive Psychology 9: 1-26.

. 1996b. "Voicing the Self: From Information Processing to Dialogical Interchange." Psychological Bulletin 119: 31-50.

2002. "The Dialogical Self as a Society of Mind." Theory and Psychology 12: 147-61.

Hermans, H. J. M., T. I. Rijks, and H. J. G. Kempen. 1993. "Imaginal Dialogues in the Self: Theory and Method." Journal of Personality 61: 207-36.

Holma, J., and J. Aaltonen. 1995. "The Self-Narrative and Acute Psychosis." Contemporary Family Therapy 17: 307-16.

.1997. "The Sense of Agency and the Search for Narrative in Acute Psychosis." Contemporary Family Therapy 19: 463-77.

Hume, David. 1888 [1734]. A Treatise of Human Nature. Oxford: Oxford University Press.

Jaynes, J. 1976. The Origins of Consciousness in the Breakdown of the Bicameral Mind. Boston: Houghton Mifflin.

Karon, B. P., and G. R. Van Denbos. 1981. Psychotherapy of Schizophrenia: The Treatment of Choice. New York: Jason Aronson.

Kendell, R. E., K. Mclnneny, E. Juszcak, and M. Bain. 2000. "Obstetric Complications and Schizophrenia: Two Case Control Studies Based on Structured Obstetric Records." British Journal of Psychiatry 176: 516-26.

Kierkegaard, S. 1980 [1849]. The Sickness unto Death. Princeton: Princeton University Press. 1992 [1846]. The Concluding Unscientific Postscripts. Princeton: Princeton University Press.

Kline, J., D. Horn, and C. M. Patterson. 1996. "Meaning and Development in the Interpersonal Treatment of Severe Psychopathology." Bulletin of the Menninger Clinic 60: 314-15.

Kraeplin, E. 1974 [1911]. Lecture on Clinical Psychiatry. Trans. Thomas Johnson. New York: Hairier.

Laing, R. D. 1978. The Divided Self. New York: Penguin Books.

Leudar, I., and P. Thomas. 2000. Voices of Reason, Voices of Insanity: Studies of Verbal Hallucinations. London: Routledge.

Lysaker, J. T. 1996. "The Shape of Selves to Come: Rorty and Self Creation." Philosophical and Social Criticism 22: 39-74.

Lysaker, P. H., and M. D. Bell. 1995. "Work and Meaning: Disturbance of Volition and Vocational Dysfunction in Schizophrenia." Psychiatry 58.4: 392-400.

Lysaker, P. H., M. D. Bell, G. J. Bryson, and E. Kaplan. 1998. "Psychosocial Function and Insight in Schizophrenia." Journal of Nervous and Mental Disease 186: 432-36.

Lysaker, P. H., C. A. Clements, C. Placak Hallberg, S. J. Knipschure, and D. E. Wright. 2002. "Insight and Personal Narratives of Illness in Schizophrenia." Psychiatry 65: 197-206.

Lysaker, P. H., and C. F. France. 1999. "Psychotherapy as an Element in Supported Employment for Persons with Severe Mental Illness." Psychiatry 62: 209-22.

Lysaker, P. H., and J. T. Lysaker. 2001a. "Psychosis and the Disintegration of Dialogical SelfStructure: Problems Posed by Schizophrenia for the Maintenance of Dialogue." British Journal of Medical Psychology 74: 23-33.

2001b. "Schizophrenia and the Collapse of the Dialogical Self: Recovery, Narrative, and Psychotherapy." Psychotherapy 38: 252-61.

2002. "Narrative Structure in Psychosis: Schizophrenia and Disruptions in the Dialogical Self." Theory and Psychology 12: 207-20.

Lysaker, P. H.,A. M. Wickett, N. Wilke, and J. T. Lysaker. Forthcoming. "Narrative Incoherence in Schizophrenia: The Absent Protagonist, Neurocognitive Impairments, and Fear of Audience." American Journal of Psychotherapy.

Mandelstam, O. 1979 [1919]. The Complete Critical Prose and Letters. Ann Arbor: Ardis. 
Markowitz, F. E. 1998. "The Effects of Stigma on the Psychological Well-Being and Life Satisfaction of Persons with Mental Illness." Journal ofHealth and Social Behavior 39: 335-47.

McGhie, A., and J. Chapman. 1961. "Disorders of Attention and Perception in Early Schizophrenia." British Journal ofMedical Psychology 34: 103-15.

Mead, G. H. 1967 [1934]. Mind, Self, and Society. Chicago: University of Chicago Press.

Minkowski, E. 1987. "The Essential Disorder Underlying Schizophrenia and Schizophrenic Thought." In The Clinical Roots of the Schizophrenic Concept, ed. J. Cutting and M. Shepherd, 188-212. Cambridge: Cambridge University Press.

Nayani, T. H., and A. S. David. 1996. "The Auditory Hallucination: A Phenomenological Survey." Psychological Medicine 26: 177-89.

Nietzsche, F. 1966 [1886]. Beyond Good and Evil. New York: Random House. . 1974 [1882]. The Gay Science. New York: Random House.

Porte, J., and S. Morris, eds. 2001. Emerson's Prose and Poetry. New York: W. W. Norton. Robbins, M. 1993 Experiences ofSchizophrenia. New York: Guilford Press.

Roe, D., and A. B. Ben-Yaskai. 1999. "Exploring the Relationship Between the Person and the Disorder Among Individuals Hospitalized for Psychosis." Psychiatry 62: 372-80.

Rosenfeld, H. 1954. "Considerations Regarding the Psychoanalytic Approach to Acute and Chronic Schizophrenia." International Journal of Psychoanalysis 39: 274-75.

Rudge, T., and K. Morse. 2001. "Re-awakening?: A Discourse Analysis of the Recovery from Schizophrenia after Medication Change." A ustralian and New Zealand Journal ofMental Health Nursing 10: 66-76.

Sass, L. A. 1992. "Heidegger, Schizophrenia, and the Ontological Difference." Philosophical Psychology 5: 109-33.

Schneider, K. 1959 Clinical Psychopathology. New York: Grune \& Stratton.

Schwartz, R. C. 1998. "The Relationship between Insight, Illness, and Treatment Outcome in Schizophrenia." Psychiatric Quarterly 69: 1-22.

Searles, H. 1965. Collected Papers ofSchizophrenia and Related Subjects. New York: International Universities Press.

Selzer, M. A., and F. Schwartz. 1994. "The Continuity of Personality in Schizophrenia." Journal of Psychotherapy Practice and Research 3: 313-24.

Spitzer, M. 1997. "A Cognitive Neuroscience View of Schizophrenic Thought Disorder." Schizophrenia Bulletin 23: 29-50

Startup, M. E. 1996. "Insight and Cognitive Deficits in Schizophrenia: Evidence for a Curvilinear Relationship." Psychological Medicine 26: 1277-81.

Szasz, T. S. 1970. The Manufacture ofMadness. New York: Harper \& Row.

Vygotsky, L. S. 1978. Mind in Society. Cambridge, MA: Harvard University Press.

Wahlberg, K. E., L. C. Wynne, H. Oja, P. Keskitalo, H. Anais-Tanner, P. Koistinen, T. Tarvainen, H. Hakko, J. Moring, M. Naarala, A. Sorri, and P. Tienari. 2002. "Thought Disorder Index of Finnish Adoptees and Communication Deviance of Their Adoptive Parents." Psychological Medicine 30: 127-36.

Warner, R., D. Taylor, M. Powers, and R. Hyman. 1989. "Acceptance of the Mental Illness Label by Psychotic Patients: Effects on Functioning." American Journal ofOrthopsychiatry 59: 389-409.

Wexler, M. 1971. "Schizophrenia as Conflict and Deficiency." Psychoanalytic Quarterly 40: 83-100. Whicher, Stephen, et al., eds. 1964 [1836]. The Early Lectures ofRalph Waldo Emerson. Vol. 2, 1836-1838. Cambridge, MA: Harvard University Press.

Wright, E. R., W. P. Gronfein, and T. J. Owens. 2000. "Deinstitutionalization, Social Rejection, and the Self Esteem of Former Mental Patients." Journal ofHealth and Social Behavior 41: 68-90.

Young, S. L., and D. S. Ensign. 1999. "Exploring Recovery from the Perspective of Persons with Psychiatric Disabilities." Psychosocial Rehabilitation Journal 22: 219-31. 